\title{
Will They Do As We Wish? An Investigation of the Effectiveness of Parental Manipulation on Mating Behavior
}

\author{
Menelaos Apostolou • Kristia Kasapi • Andri Arakliti
}

Published online: 21 November 2014

(C) Springer International Publishing 2014

\begin{abstract}
Parents have vested interests in their children's mating behavior. Accordingly, they employ a battery of tactics to manipulate the mate choices of their daughters and sons. This paper attempts to investigate how effective these tactics are in accomplishing this goal and which tactics are more effective than others. It aims further to investigate how accurately parents can assess the effectiveness of their manipulation tactics. Evidence from two independent studies indicates that parental manipulation has an effect which is, nevertheless, small with some tactics being more effective than others. It is also found that parents accurately assess the effectiveness of their manipulation on mating behavior. The implications of these findings are further discussed.
\end{abstract}

Keywords Mating behavior $\cdot$ Manipulation tactics $\cdot$ Parental manipulation

\section{Introduction}

Parents have a strong interest in their children's mating behavior. Their daughters and sons, however, are likely to make choices which do not agree with their wishes (Apostolou 2014; Buunk et al. 2008; Perilloux et al. 2011) so they resort to manipulation in order to align their children's behavior to their will (Apostolou 2014). Research has identified several tactics that parents employ for this purpose (Apostolou 2013); yet, there has not been any attempt to explore the effectiveness of these tactics in influencing children's behavior. The purpose of the present research is to contribute to the literature by attempting to assess how effective the parental manipulation

M. Apostolou $(\bowtie) \cdot$ K. Kasapi $\cdot$ A. Arakliti

University of Nicosia, 46 Makedonitissas Ave.,

2414 Nicosia, Cyprus

e-mail: m.apostolou@gmail.com tactics are in influencing mating decisions. It further attempts to explore whether parents can accurately assess the effectiveness of their manipulation tactics on mating behavior.

Agreement and Disagreement Over Mate Choice

Parents and children are genetically related, but not genetically identical. The consequence of this is that their genetic interests overlap, but also diverge, with mating being one area where this is manifested (Trivers 1974). In particular, because parents have overlapping interests with their children, if their children get involved with mates who have undesirable qualities (they are, for instance, abusive), this will compromise their fitness (i.e., their reproductive success) because such mates are likely to reduce their children's fitness, and consequently, their own. Yet, their children may not always make fitness-increasing choices. For instance, they may be carried away in relationships with individuals who physically abuse them or who do not intend to establish a committed relationship. As this decreases, in the fitness of children and their parents, the latter have the incentive to intervene in order to correct the situation (Apostolou and Papageorgi 2014). And parents can be effective in doing so because they are older and more experienced, and their judgment is not clouded by high levels of libido or love; so in many instances, they may be better able to identify cost-inflicting mates than their children.

In addition, because the two parties are not genetically identical, certain traits in a prospective mate make different fitness contributions to each party. If we take good genetic quality as an example, the coefficient of relatedness of parents to children is 0.5 , but the coefficient of relatedness of grandparents to grandchildren is half as much, namely, 0.25 . This means that parents obtain fewer genetic benefits from a prospective in-law than their children from a prospective mate of high genetic quality (Apostolou 2008; Buunk et al. 2008). In effect, although both children and parents would prefer a mate 
and an in-law, respectively, to be of good genetic quality, children would place more emphasis on this trait than their parents (Apostolou 2008).

Research has identified several traits, including beauty (a proxy of genetic quality), good family background, exciting personality, and similar religious background, which are preferred differently by parents and their children (Apostolou 2014; Buunk et al. 2008; Dubbs and Buunk 2010; Perilloux et al. 2011). This indicates that when they choose a mate, children are likely to find spouses who do not comply with the preferences of their parents. For instance, they may compromise in traits such as good family background, which is preferred more by parents, to get traits such as beauty. These compromises are not optimal for parents who are motivated to intervene on their children's mating decisions.

Consistent with this, in one study, when children and their parents were given a budget of mate points in order to design a spouse and an in-law, respectively, children saved on traits such as good family background and similar religious background to get more of good looks and exciting personality (Apostolou 2011). Their parents, on the other hand, saved on beauty and exciting personality to get more of good family background and similar religious background. Children also saved more than their parents on traits that relate to the provision of resources such as favorable social status, ambition, and industriousness. Thus, children's mate choices lead to compromises that parents would not make if they were to exercise the choice for their children.

Overall, converging and diverging interests motivate parents to exercise influence over their children's mating behavior. In a pre-industrial context, parents can exercise direct control over their daughters' and sons' mating behavior and impose on them their in-law choices (Broude and Green 1983; Stephens 1963). In particular, across pre-industrial societies, the most common mode of long-term mating is arranged marriage where parents choose spouses for their children (Apostolou 2014). Parents can achieve direct control in this context because they can apply physical force on their children and because their children of marriageable age are dependent on parental investment (Apostolou 2010). In postindustrial societies, however, the rule of law and the protection of individual rights constrain parents from applying physical force on their daughters and sons, while marriage usually takes place at an age when children are financially independent from their parents (Apostolou 2014). In consequence, parents cannot control mating directly and they have to resort to manipulation in order to do so indirectly.

\section{Mating and Manipulation}

Manipulation is employed in a wide variety of settings, and research has identified broader categories of distinct manipulation tactics that consist of a plethora of manipulation acts
(Buss 1988, 1992; Buss et al. 1987; Buss and Shackelford 1997; de Miguel and Buss 2011). Buss (1992) identified 12 tactics, which are used by individuals, including parents, who have the intention of manipulating others. Each is composed of several distinct acts of manipulation, for instance, the "Debasement" tactic involves acts such as "Lower myself so she'll do it." These tactics are expected to differ according to the situation and according to the goals toward which they are directed (Buss et al. 1987). Existing research does not provide, however, adequate information on the battery of tactics that are employed by parents to manipulate mate choice.

A number of studies provide information on the specific tactics that parents employ in order to manipulate mate choice. More specifically, Sussman (1953) reported means such as "cajolery, persuasion, appeals to loyalty, and threats" to be used by parents in order to influence their children's mating behavior. Another study found that modern Chinese parents in the USA attempt to create environments, such as staging a barbecue, in which their children can meet other individuals of Chinese descent, and therefore, of desirable background (Ikels 1985).

The full extent of parental manipulation fails to be accounted for in these studies because they were not specifically designed for this purpose. In order for this limitation to be addressed, one study identified several acts that parents use on their children to manipulate their mate choices by employing a series of interviews with parents and younger individuals who had no children (Apostolou 2013). Because the parents' influence of mate choice can also take place through their children's mates, this research also identified several acts that are used by parents for this purpose. For instance, parents can attempt to break the relationship of their daughter with an undesirable mate by employing manipulation on him to drive him away. In a subsequent study, parents were asked to indicate how likely they were to use these tactics on their children and on their children's mates. By applying principal components analysis, these acts were classified in 12 tactics that parents use on their children and four tactics that they use on their children's mates.

The battery of manipulation tactics that parents have at their disposal raises the question of whether these tactics are indeed influential over mating behavior. Evolutionary reasoning would suggest that this is the case. In particular, parents can develop manipulation that is effective on their children. In turn, this exercises evolutionary pressure on children to become resistant to such manipulation, which in turn exercises pressure on parents to develop better means of manipulation, and so this process goes on. It follows that a situation where children are totally resistant to this manipulation is unlikely. Accordingly, it is predicted that children would be sensitive to their parents' manipulation; that is, parents' manipulation will be to some degree effective in changing children' minds.

Moreover, there are several tactics of manipulation, but it is unlikely that all of them would be equally effective. For 
instance, giving a threat may be less effective than giving an advice as the former may cause children to react against their parents will. Accordingly, this research aims, first, to investigate whether the manipulation that parents employ is influential on mating behavior, and second, to identify which tactics are more effective and which are less effective. It aims further to explore whether parents can accurately assess the effectiveness of their manipulation tactics. Finally, it aims to investigate several contingencies including whether the effectiveness of manipulation depends on the sex of the child.

\section{Study 1}

The purpose of study 1 is to attempt to measure how effective parental manipulation is in influencing individuals' mating behavior.

\section{Method \\ Participants}

Two research assistants were employed for purposes of this study. They recruited individuals who volunteered to participate in a research study on family relationships (no payment was given). In order to qualify for participation, an individual had to be an adult (i.e., 18 years and older), but it was not required to be a parent. A snowball sampling technique was used where the research assistants first recruited several individuals and then obtained references for others who might have been interested in participating in the study. The research took place in the Republic of Cyprus, and the participants came predominantly from the two biggest cities of the republic, namely Nicosia and Limassol. The data collection process lasted approximately 1 month. The participants were initially asked to sign a consent form, and then, they were given the survey. Upon completion, they put the questionnaire in an unmarked enveloped and sealed it.

Participants included 213 Greek-Cypriots (125 women, 86 men, and 2 participants who did not indicate their sex). The mean age of women was $30.7(\mathrm{SD}=8.6)$, and the mean age of men was $30.4(\mathrm{SD}=9)$. Moreover, $39.2 \%$ of the participants were married, $37.3 \%$ were single, $17.5 \%$ were in a relationship, and $6.1 \%$ were divorced. Please note that the participants' sexual orientation was not recorded.

\section{Materials}

The survey consisted of three parts. In the first part, participants were asked to rate 63 acts of manipulation, identified by
Apostolou (2013), which are likely to be used by their parents in order to manipulate them. The following scenario was given:

Below you will find a series of acts that your parents may do in order to influence your behavior with respect to romantic relationships. Read each act and indicate how likely it is to influence your behavior.

In the second part, participants were asked to rate 26 acts of manipulation, identified by Apostolou (2013), which are likely to be used by the parents of the individuals' mates in order to manipulate them. The following scenario was given:

Below you will find a series of acts that the parents of your mates may do in order to influence your romantic relationship with their daughters/sons. Read each act and indicate how likely it is to influence your behavior.

In both parts, the participants' responses were recorded in a seven-point Likert scale which ranged from 1="not at all likely to influence me," to $7=$ "extremely likely to influence me." In the third part, participants were asked to indicate their demographic information (sex, age, marital status). Finally, the order of presentation of part one and two was counterbalanced across participants.

\section{Results}

\section{Tactics Employed on Children}

\section{Effectiveness}

To assess the overall effectiveness of manipulation, a grand mean was estimated by averaging the scores that participants gave for each act. The mean score of the grand mean variable is $2.34(\mathrm{SD}=1.13)$, indicating a small overall impact of parental manipulation on mating behavior. However, some tactics are more effective and some are less effective than the grand mean indicates. Accordingly, to assess the effectiveness of each tactic, means and standard deviations were estimated by averaging the scores that participants gave for the acts composing each tactic.

The results are presented in Table 1 (the individual acts composing each tactic can be found in Apostolou 2013). We can see that participants indicated that they are more likely to be influenced by tactics such as the "advice and reasoning," the "silent treatment" and the "whom one should marry," and less likely to be influenced by tactics such as the "hardball" and the "matchmaker."

\section{Contingencies}

For the purposes of this analysis, a series of multivariate analysis of covariances (MANCOVAs) was performed where 
Table 1 The effectiveness of manipulation tactics employed on children

\begin{tabular}{|c|c|c|c|c|c|c|c|c|}
\hline Tactics & Rank individuals & $\begin{array}{l}\text { Overall } \\
\text { Mean (SD) }\end{array}$ & $\begin{array}{l}\text { Women } \\
\text { Mean (SD) }\end{array}$ & $\begin{array}{l}\text { Men } \\
\text { Mean (SD) }\end{array}$ & Rank parents & $\begin{array}{l}\text { Overall } \\
\text { Mean (SD) }\end{array}$ & $\begin{array}{l}\text { Daughters } \\
\text { Mean (SD) }\end{array}$ & $\begin{array}{l}\text { Sons } \\
\text { Mean (SD) }\end{array}$ \\
\hline Advice and reasoning & 1 & $3.31(1.52)$ & $3.53(1.56)$ & $3.02(1.43)$ & 1 & $3.84(1.67)$ & $3.88(1.68)$ & $3.85(1.81)$ \\
\hline Silent treatment & 2 & $3.18(1.53)$ & $3.17(1.52)$ & $3.17(1.56)$ & 3 & $2.81(1.14)$ & $2.82(1.27)$ & $2.90(1.22)$ \\
\hline Whom one should marry & 3 & $2.97(1.47)$ & $3.06(1.47)$ & $2.85(1.47)$ & 2 & $3.53(1.37)$ & $3.59(1.43)$ & $3.36(1.41)$ \\
\hline Social comparison & 4 & $2.90(1.58)$ & $2.99(1.61)$ & $2.75(1.55)$ & 5 & $2.64(1.08)$ & $2.72(1.20)$ & $2.60(1.29)$ \\
\hline Use relatives and friends & 5 & $2.71(1.40)$ & $2.69(1.30)$ & $2.73(1.54)$ & 6 & $2.66(1.02)$ & $2.64(1.20)$ & $2.74(1.08)$ \\
\hline Guilt trip & 6 & $2.58(1.43)$ & $2.66(1.45)$ & $2.47(1.42)$ & 10 & $2.17(0.82)$ & $2.28(0.95)$ & $2.09(0.89)$ \\
\hline Carrot and stick & 7 & $2.41(1.26)$ & $2.39(1.12)$ & $2.45(1.46)$ & 7 & $2.52(1.15)$ & $2.55(1.14)$ & $2.45(1.25)$ \\
\hline Prevention & 8 & $2.32(1.38)$ & $2.43(1.34)$ & $2.18(1.42)$ & 4 & $2.56(1.15)$ & $2.73(1.26)$ & $2.40(1.21)$ \\
\hline Coercion & 9 & $2.29(1.35)$ & $2.24(1.29)$ & $2.36(1.44)$ & 12 & $2.04(0.91)$ & $2.13(1.04)$ & $2.01(0.93)$ \\
\hline Chaperoning & 10 & $2.27(1.22)$ & $2.25(1.12)$ & $2.30(1.36)$ & 8 & $2.43(0.88)$ & $2.46(0.96)$ & $2.48(0.89)$ \\
\hline Matchmaker & 11 & $2.22(1.30)$ & $2.08(1.10)$ & $2.44(1.54)$ & 9 & $2.25(0.89)$ & $2.31(0.97)$ & $2.17(0.97)$ \\
\hline Hardball & 12 & $2.19(1.33)$ & $2.06(1.22)$ & $2.18(1.42)$ & 12 & $1.75(0.77)$ & $1.80(0.85)$ & $1.71(0.77)$ \\
\hline
\end{tabular}

participants' answers for the questions composing each tactic were entered as the dependent variables and the participants' sex, marital status, and age, entered as the independent variables.

The results are presented in Table 2. We can see that there is a significant main effect of age for the "advice and reasoning," the "silent treatment," and the "use relatives and friends." The coefficient of age came with a negative coefficient indicating that older individuals consider this tactic to be less effective on them than younger ones. Furthermore, we can see a significant main effect of sex for the "advice and reasoning" with women indicating a higher influence than men, and for the "carrot and stick" with men indicating that they are more likely to be affected than women. In addition, a significant main effect of marital status was found for the "advice and reasoning," the "whom one should marry," the "guilt trip," and the "hardball" tactics.

Finally, we can see that there was a significant interaction between sex and marital status for the "use of relatives and friends" tactic with men who are divorced being affected more than women; that is, men who were divorced indicated to be more influenced by manipulation than women who were divorced, but married, single, and in a relationship men and women indicated a similar degree of influence. This was also the case for the "guilt trip," with divorced men and men in a relationship to be affected more than women; for the "carrot and stick," where men who are divorced and in a relationship were affected more than women; for the "prevention," where men who are divorced were affected more than women; for the "coercion," with divorced men reporting that they are

Table 2 The contingencies of manipulation tactics employed on children in study 1

\begin{tabular}{|c|c|c|c|c|c|c|c|c|}
\hline \multirow[t]{2}{*}{ Tactics } & \multicolumn{2}{|l|}{ Age } & \multicolumn{2}{|l|}{ Sex } & \multicolumn{2}{|c|}{ Marital status } & \multicolumn{2}{|c|}{ Marital status* Sex } \\
\hline & $p$ value & $\eta p^{2}$ & $p$ value & $\eta p^{2}$ & $p$ value & $\eta p^{2}$ & $p$ value & $\eta p^{2}$ \\
\hline Advice and reasoning & .041 & .052 & .011 & .068 & .029 & .040 & n.s. & n.s. \\
\hline Silent treatment & .008 & .049 & n.s. & n.s. & n.s. & n.s. & n.s. & n.s. \\
\hline Whom one should marry & n.s. & n.s. & n.s. & n.s. & .027 & .061 & n.s. & n.s. \\
\hline Social comparison & n.s. & n.s. & n.s. & n.s. & n.s. & n.s. & n.s. & n.s. \\
\hline Use relatives and friends & .013 & .057 & n.s. & n.s. & n.s. & n.s. & .041 & .030 \\
\hline Guilt trip & n.s. & n.s. & n.s. & n.s. & .022 & .049 & .004 & .058 \\
\hline Carrot and stick & n.s. & n.s. & .047 & .059 & n.s. & n.s. & .005 & .056 \\
\hline Prevention & n.s. & n.s. & n.s. & n.s. & .022 & .049 & .041 & .030 \\
\hline Coercion & n.s. & n.s. & n.s. & n.s. & n.s. & n.s. & $<.001$ & .121 \\
\hline Chaperoning & n.s. & n.s. & n.s. & n.s. & n.s. & n.s. & .007 & .087 \\
\hline Matchmaker & n.s. & n.s. & n.s. & n.s. & n.s. & n.s. & n.s. & n.s. \\
\hline Hardball & n.s. & n.s. & .026 & .108 & n.s. & n.s. & n.s. & n.s. \\
\hline
\end{tabular}


affected more than divorced women, and for the "chaperoning," where men who are in a relationship appear to be affected more than women of equivalent marital status.

Tactics Employed on In-Laws

\section{Effectiveness}

To assess the overall effectiveness of manipulation, a grand mean was estimated by averaging the scores that participants gave for each act. The grand mean is $2.54(\mathrm{SD}=1.20)$, indicating a small overall impact of parental manipulation. In order to assess the effectiveness of each tactic, means and standard deviations were estimated by averaging the scores that participants gave for the acts composing each tactic.

The results are presented in Table 3. We can see that participants indicated the "we are family" as the tactic which is likely to influence them most. This was followed by the "dirty laundry," the "hardball" and the "lure" tactics.

\section{Contingencies}

As above, a series of MANCOVAs was performed where participants' answers for the questions composing each tactic were entered as the dependent variables and the participants' sex, marital status, and age, were entered as the independent variables. The results can be seen in Table 4 .

We can see that no significant main effects for the age were produced. There was, however, a significant main effect of sex for the "we are family" tactic, with women indicating that they are more likely to be affected than men. For this tactic, there was also a significant main effect of marital status, with those in a relationship and married indicating that they are more likely to be affected than the rest. There was also a significant main effect of marital status for the "dirty laundry," with those in a relationship and those that are married indicating that they are more likely to be affected than the rest. There was also a significant interaction between sex and marital status, with men who were divorced or in a relationship to be affected more than women. That is, men who were divorced or in a relationship indicated to be more influenced by manipulation than women who were divorced or in a relationship, but married and single men and women indicated a similar degree of influence. Finally, such an interaction was found for the "lure" tactic, with men who were divorced or in a relationship to be affected more than women.

\section{Study 2}

The purpose of study 2 is to examine whether parents have an accurate perception of the effectiveness of their manipulation tactics on altering mating behavior.

\section{Method}

Participants

Two research assistants were employed for the purposes of this study. They recruited individuals who volunteered to participate in a research study on family relationships (no payment was given). In order to qualify for participation, an individual had to have at least one male and one female child. A snowball sampling technique was employed where the research assistants recruited first several parents and then obtained references for other parents who might have been interested in participating in the study. The research took place in the Republic of Cyprus, and the participants came predominantly from the two biggest cities of the Republic, namely Nicosia and Limassol. The data collection process lasted approximately two months. This study did not employ couples, that is, fathers and mothers came from different families. The participants were initially asked to sign a consent form, and then, they were given the survey. Upon completion, the participants put the questionnaire in an unmarked enveloped and sealed it.

In this study, 243 Greek-Cypriots took part (128 women and $115 \mathrm{men})$. The mean age of mothers was $45.5(\mathrm{SD}=13.2)$, and the mean age of fathers was $46.2(\mathrm{SD}=13.64)$. Moreover, $82.2 \%$ of the participants were married, $9.1 \%$ were divorced, $4.1 \%$ were in a relationship, $3.7 \%$ were single, and $0.8 \%$ were widowed.

Table 3 The effectiveness of manipulation tactics employed on in-laws

\begin{tabular}{|c|c|c|c|c|c|c|c|c|}
\hline Tactics & Rank individuals & $\begin{array}{l}\text { Overall } \\
\text { Mean (SD) }\end{array}$ & $\begin{array}{l}\text { Women } \\
\text { Mean (SD) }\end{array}$ & $\begin{array}{l}\text { Men } \\
\text { Mean (SD) }\end{array}$ & Rank parents & $\begin{array}{l}\text { Overall } \\
\text { Mean (SD) }\end{array}$ & $\begin{array}{l}\text { Daughters-in-law } \\
\text { Mean (SD) }\end{array}$ & $\begin{array}{l}\text { Sons-in-law } \\
\text { Mean (SD) }\end{array}$ \\
\hline We are family & 1 & $3.82(1.76)$ & 4.05 (1.79) & $3.54(1.71)$ & 1 & $3.61(1.39)$ & $3.67(1.50)$ & $3.59(1.52)$ \\
\hline Dirty laundry & 2 & $2.89(1.74)$ & $2.87(1.81)$ & $2.95(1.83)$ & 2 & $2.49(1.02)$ & $2.49(1.11)$ & $2.49(1.11)$ \\
\hline Hardball & 3 & $2.88(1.90)$ & 2.84 (1.97) & $2.92(1.66)$ & 4 & $1.72(0.84)$ & $1.73(0.92)$ & $1.73(0.93)$ \\
\hline Lure & 4 & $2.59(1.57)$ & $2.51(1.52)$ & $2.72(1.65)$ & 3 & $2.35(1.21)$ & $2.38(1.24)$ & $2.29(1.29)$ \\
\hline
\end{tabular}


Table 4 The contingencies of manipulation tactics employed on in-laws in study 1

\begin{tabular}{|c|c|c|c|c|c|c|c|c|}
\hline \multirow[t]{2}{*}{ Tactics } & \multicolumn{2}{|l|}{ Age } & \multicolumn{2}{|l|}{ Sex } & \multicolumn{2}{|c|}{ Marital status } & \multicolumn{2}{|c|}{ Marital status* Sex } \\
\hline & $p$ value & $\eta p^{2}$ & $p$ value & $\eta p^{2}$ & $p$ value & $\eta p^{2}$ & $p$ value & $\eta p^{2}$ \\
\hline We are family & n.s. & n.s. & .024 & .069 & .004 & .059 & n.s. & n.s. \\
\hline Dirty laundry & n.s. & n.s. & n.s. & n.s. & .050 & .044 & .011 & .053 \\
\hline Hardball & n.s. & n.s. & n.s. & n.s. & n.s. & n.s. & n.s. & n.s. \\
\hline Lure & n.s. & n.s. & n.s. & n.s. & n.s. & n.s. & .018 & .035 \\
\hline
\end{tabular}

\section{Method}

The survey consisted of three parts. In the first part, participants were asked to rate the effectiveness of the 63 acts employed in study 1 on their children. The following scenario was given:

Below you will find a series of acts that parents may do in order to influence the behavior of their children with respect to romantic relationships. Read each act and indicate how effective you think it will be in influencing your daughter's/son's behavior.

Participants were asked to rate the acts twice, once for their daughters and once for their sons. In the second part, participants were asked to rate the effectiveness of the 26 acts employed in study 1 on their children's mates. The following scenario was given:

Below you will find a series of acts that parents may do in order to influence the behavior of their children's mates. Read each act and indicate how effective you think it will be in influencing your daughter's/son's mate's behavior.

Participants rated the traits twice, once for their daughters' mates and once for their sons' mates. In both parts, participants' responses were recorded in a seven-point Likert scale which ranged from 1="not at all effective" to 7="extremely effective." In the third part, participants were asked to indicate their demographic information (sex, age, and marital status). Finally, the order of presentation of parts one and two, as well as the order of presentation of children (daughters and sons) and of children's mates (daughter's mate and son's mate), was counterbalanced across participants.

\section{Results}

Tactics Employed on Children

\section{Effectiveness}

To assess how effective parents consider their manipulation tactics to be, a grand mean was estimated by averaging the scores that participants gave for each act. The grand mean was $2.41(\mathrm{SD}=0.77)$, indicating that parents consider that their manipulation will not have an overall large effect on their children's mating behavior. This is in agreement with the results of study 1 where individuals indicated that parental manipulation will have a small effect on their mating decisions. However, some tactics may be considered more effective and some less effective, than the grand mean indicates. Accordingly, to assess how effective each tactic is considered, means and standard deviations were estimated by averaging the scores that participants gave for the acts composing each tactic.

The results are presented in Table 1 where we can see that parents considered tactics such as the "advice and reasoning" and the "whom one should marry" to be more effective than tactics such as the "hardball" and the "coercion."

\section{Contingencies}

In order to identify contingencies, a doubly multivariate analysis (which is statistically equivalent to the repeated measures MANOVA) was conducted for each of the 12 manipulation tactics. Note that this statistical tool was used because it allows the independent variables to be within-participants (in this case of the sex of the child). In each comparison, the sex of the child, the sex of the parent, and the age of the parents were entered as the independent variables and the acts that composed each tactic were entered as the dependent variables. The results are presented in Table 5 .

With the exception of the "carrot and stick" and the "hardball" tactics, for all other tactics, there was a significant main effect of age with a negative coefficient indicating that older individuals consider these tactic to be less effective on them than younger ones. For these tactics, there was a significant main effect of the sex of child with parents indicating that their female children will be affected more.

Tactics Employed on In-Laws

\section{Effectiveness}

For the purpose of assessing how effective parents consider their manipulation to be on their children's mates, a grand 
Table 5 The contingencies of manipulation tactics employed on children in study 2

\begin{tabular}{|c|c|c|c|c|c|c|}
\hline \multirow[t]{2}{*}{ Tactics } & \multicolumn{2}{|l|}{ Age } & \multicolumn{2}{|c|}{ Sex child } & \multicolumn{2}{|c|}{ Sex parent } \\
\hline & $p$ value & $\eta p^{2}$ & $p$ value & $\eta p^{2}$ & $p$ value & $\eta p^{2}$ \\
\hline Advice and reasoning & $<.001$ & .210 & n.s. & n.s. & n.s. & n.s. \\
\hline Silent treatment & $<.001$ & .135 & n.s. & n.s. & n.s. & n.s. \\
\hline Whom one should marry & $<.001$ & .134 & n.s. & n.s. & n.s. & n.s. \\
\hline Social comparison & .001 & .053 & n.s. & n.s. & n.s. & n.s. \\
\hline Use relatives and friends & $<.001$ & .070 & n.s. & n.s. & n.s. & n.s. \\
\hline Guilt trip & .004 & .042 & n.s. & n.s. & n.s. & n.s. \\
\hline Carrot and stick & n.s. & n.s. & .022 & .063 & n.s. & n.s. \\
\hline Prevention & $<.001$ & .147 & n.s. & n.s. & n.s. & n.s. \\
\hline Coercion & .044 & .021 & n.s. & n.s. & n.s. & n.s. \\
\hline Chaperoning & .003 & .043 & n.s. & n.s. & n.s. & n.s. \\
\hline Matchmaker & .048 & .026 & n.s. & n.s. & n.s. & n.s. \\
\hline Hardball & n.s. & n.s. & .001 & .137 & n.s. & n.s. \\
\hline
\end{tabular}

mean was estimated by averaging the scores that participants gave for each act employed on their daughters' and sons' mates. The grand mean was $2.35(\mathrm{SD}=0.81)$, indicating that parents considered that their manipulation will not have an overall small effect on their children's mates. This is consistent with the results of study 1 , where individuals indicated that their mate's parents' manipulation will have a small effect on their mating decisions.

\section{Contingencies}

As before, in order to identify contingencies, a doubly multivariate analysis was conducted for each of the four manipulation tactics. In each comparison, the sex of the child's mate, the sex of the parent, and the age of the parents were entered as the independent variables and the acts that composed each tactic were entered as the dependent variables. The results are presented in Table 6.

We can see that there is a significant main effect of age for the "lure" tactic with a negative coefficient indicating that older parents consider their manipulation to be less effective

Table 6 The contingencies of manipulation tactics employed on in-laws in study 2

\begin{tabular}{|c|c|c|c|c|c|c|}
\hline \multirow[t]{2}{*}{ Tactics } & \multicolumn{2}{|l|}{ Age } & \multicolumn{2}{|c|}{ Sex child } & \multicolumn{2}{|c|}{ Sex parent } \\
\hline & $p$ value & $\eta p^{2}$ & $p$ value & $\eta p^{2}$ & $p$ value & $\eta p^{2}$ \\
\hline We are family & n.s. & n.s. & n.s. & n.s. & n.s. & n.s. \\
\hline Dirty laundry & n.s. & n.s. & n.s. & n.s. & .006 & .081 \\
\hline Hardball & n.s. & n.s. & n.s. & n.s. & n.s. & n.s. \\
\hline Lure & .042 & .021 & n.s. & n.s. & n.s. & n.s. \\
\hline
\end{tabular}

than younger ones. Also, for the "we are family" tactic there was also a significant main effect of the sex of the parent, with mothers, more than fathers, indicating that the mates of their children will be affected by this tactic.

\section{Correlations}

In order to examine whether parents can accurately assess the effectiveness of their manipulation tactics, Spearman's correlation was applied on the rankings of the manipulation tactics of study 1 (which indicate the tactics individuals consider more or less likely to influence them) and the rankings of the manipulation tactics in study 2 (which indicate the tactics parents think will be more or less influential). The results indicated a significant strong and positive correlation $[r(12)=.874, p<.001$ (two-tailed) $]$ that hints that parents can accurately assess the effectiveness of their manipulation. In addition, Spearman's correlation was applied on the rankings that women gave for themselves and the rankings parents gave for daughters. The results indicated a significant strong and positive correlation $[r(12)=.869, p<.001$ (two-tailed)]. Similarly, Spearman's correlation was applied on the rankings that men gave for themselves and the rankings parents gave for sons. The results indicated a significant strong and positive correlation $[r(12)=.809, p=.001$ (two-tailed)].

Finally, with respect to manipulation applied to children's mates, from Table 2, we can see an overlap in the rankings with the only difference being that the "hardball" was ranked third by individuals and fourth by parents. The correlation coefficient was strong and positive $(r=.800)$, although it did not pass the significance level, which is expected given that we have only four ranks in each case. 


\section{Discussion}

The results of study 1 indicate that manipulation can potentially affect children's mating behavior. The effect appears to be small, yet some manipulation tactics such as the "advice and reasoning" appear to be much more effective than others, such as the "hardball." The results of study 2 indicate that parents can accurately assess how effective each tactic is on influencing their children's mating behavior. Parents do not appear, however, to be able to assess whether a tactic is more effective on a daughter than on a son as for instance, they consider certain tactic more effective in a daughter than in a son while the results of study 1 indicate these tactics to be more effective in a son than in a daughter. In addition, mothers and fathers appear to be in agreement between them in assessing the effectiveness of tactics.

Moreover, study 1 found an effect of marital status for several tactics, with those being in a relationship or divorced, especially men, to indicate that they will be more affected by their parents' manipulation, than the rest. One possible explanation for this is that manipulation is not directly relevant to individuals who are single, so they are more likely to indicate that they will not be affected, than those who are in a relationship, and for whom the intervention of their parents is more relevant. Also, one of the reasons that led individuals in the sample to divorce may have been their parents' intervention, which can possibly account for why divorced people also report that they are more likely to be affected by specific tactics. The reason why, however, men who are in a relationship or divorced indicate that they are more likely to be affected than women of equivalent marital status, is unclear.

In study 2, the age of parents for almost all tactics was significant with a negative coefficient which indicates that older individuals consider their manipulation tactics to be less effective on their children than younger ones. One possible explanation for this is that older parents have older children and manipulation is less effective on older individuals. For instance, in study 1 , for several tactics, the age of individuals was significant with a negative coefficient indicating that younger individuals report manipulation to be more effective than older individuals. Future studies need to examine how effective parents consider manipulation over children of different ages.

Moreover, the manipulation tactics may have an accumulating effect. In particular, a tactic used once may have little impact on altering behavior, but the repeated use of the tactic over time can increase its effectiveness. That is, repeated acts, such as crying and whining, may result in building up pressure on children that may eventually bring desirable results. Yet, this accumulating effect has not been examined here, and future studies need to attempt to measure it.

In addition, effective manipulation is manipulation which is not considered as such (Apostolou and Papageorgi 2014); that is, individuals are more likely to be manipulated if they do not realize that they are manipulated. Nevertheless, in this research, each act is explicitly presented to participants as manipulation, a fact that can underestimate how effective each act can potentially be, in the case where individuals do not consider it as manipulation.

Furthermore, the effectiveness of a manipulation tactic is also likely to be contingent on the specific circumstances. For instance, if parents advise their children against a relationship when the relationship is going smoothly, this may not be very effective. However, if there is a fight, parents may grasp the opportunity and advise their children against this relationship, which in this case may be much more effective. If parents adapt their manipulation to the circumstances, then their manipulation tactics can be more effective than they appear to be here.

It can be argued that if parents in ancestral human societies were able to impose direct control over their children's mate choices, there have not been strong evolutionary pressures exercised on parents to evolve specific manipulation tactics to be used on their children's mate choices. Accordingly, the battery of tactics parents employ today are not manipulation tactics which have evolved specifically to control mate choice, but rather they are co-opting adaptations for manipulation in other domains. However, the anthropological and historical records indicate that even in a pre-industrial context where mate choice is regulated, children have space to exercise choice. For instance, they may escape the control of their parents and engage in intimate relationships, they may divorce the spouses their parents have selected for them, and they may manipulate their parents in accepting their choices (Apostolou 2014).

This indicates that there have been evolutionary pressures on parents to evolve ways to reduce the space that children have to exercise choice, one being manipulation. These pressures may have resulted in some co-opted adaptations for manipulation to be refined for manipulation in mating and specialized adaptations that are employed only in this domain to evolve as well. Therefore, the manipulation tactics we observe today are likely to be co-opting adaptations for manipulation in other domains as well as adaptions that have evolved to serve the purpose of manipulating offspring's mating behavior.

One limitation of this research is that it is based on selfreport data. This can introduce the bias of participants underrating or overrating how effective some tactics are likely to be when used on them. This may be because individuals are not willing to admit that their parents can influence their mating behavior. Another reason is that they may not be able to accurately estimate the effectiveness of the manipulation tactics on their behavior. Also, the present research is based on a single culture, and future studies need to investigate the effectiveness of these tactics in different cultural contexts. Moreover, there are several other factors such as personality which were not examined here, but which are likely to affect 
how influential tactics are. It can be the case, for instance, that children high in agreeableness may be more affected by certain tactics, such as the "guilt trip," than children low in agreeableness. Accordingly, future studies need to identify the factors that influence the effectiveness of manipulation tactics.

Last but not least, one limitation is that this study measures the presumed effectiveness of manipulation tactics and not the actual effectiveness. In particular, study 1 asks individuals how likely it is that specific acts would influence them with respect to their mating behavior; it does not measure however, how they actually influence them. Future research may employ a different research method such as in-depth interview to assess the actual effectiveness of manipulation tactics.

Overall, in post-industrial societies, parents, although they cannot control directly their children's mating behavior, they can still have a say, predominantly through using manipulation. Further research is required in order to identify and study the different facets of parental manipulation and its consequences.

Acknowledgments The authors would like to thank two anonymous reviewers for their constructive criticisms and comments which enabled the improvement of this work.

\section{References}

Apostolou, M. (2008). Parent-offspring conflict over mating: the case of beauty. Evolutionary Psychology, 6, 303-315.

Apostolou, M. (2010). Sexual selection under parental choice in agropastoral societies. Evolution and Human Behavior, 31, 39-47.

Apostolou, M. (2011). Parent-offspring conflict over mating: testing the tradeoffs hypothesis. Evolutionary Psychology, 9, 470-495.
Apostolou, M. (2013). Do as we wish: parental tactics of mate choice manipulation. Evolutionary Psychology, 11, 795-813.

Apostolou, M (2014) Sexual selection under parental choice: the evolution of human mating behaviour. Hove: Psychology Press

Apostolou, M., \& Papageorgi, I. (2014). Parental mate choice manipulation tactics: exploring prevalence, sex and personality effects. Evolutionary Psychology, 12, 588-620.

Broude, G. J., \& Green, S. J. (1983). Cross-cultural codes on husbandwife relationships. Ethnology, 22, 263-280.

Buss, D. M. (1988). From vigilance to violence: tactics of mate retention in American undergraduates. Ethology and Sociobiology, 9, 291317.

Buss, D. M. (1992). Manipulation in close relationships: five personality factors in interactional context. Journal of Personality, 60, 477-499.

Buss, D. M., \& Shackelford, T. K. (1997). From vigilance to violence: mate retention tactics in married couples. Journal of Personal and Social Psychology, 72, 346-361.

Buss, D. M., Gomes, M., Higgins, D. S., \& Lauterbach, K. (1987). Tactics of manipulation. Journal of Personal and Social Psychology, 52, 1219-1229.

Buunk, A. P., Park, J. H., \& Dubbs, S. L. (2008). Parent-offspring conflict in mate preferences. Review of General Psychology, 12, 47-62.

de Miguel, A., \& Buss, D. M. (2011). Mate retention tactics in Spain: personality, sex differences, and relationship status. Journal of Personality, 3, 563-586.

Dubbs, S. L., \& Buunk, A. P. (2010). Parents just don't understand: parent-offspring conflict over mate choice. Evolutionary Psychology, 8, 586-598.

Ikels, C. (1985). Parental perspectives on the significance of marriage. Journal of Marriage and Family, 47, 253-264.

Perilloux, C., Fleischman, D. S., \& Buss, D. M. (2011). Meet the parents: parent-offspring convergence and divergence in mate preferences. Personality and Individual Differences, 50, 253-258.

Stephens, W. N. (1963). The family in cross-cultural perspective. New York: Holt, Rinehart \& Winston

Sussman, M. B. (1953). Parental participation in mate selection and its effect upon family continuity. Social Forces, 1, 76-81.

Trivers, R. (1974). Parent offspring conflict. American Zoologist, 24, 249-264. 